\title{
DE ONDE VÊM OS NOMES DAS VIDRARIAS DE LABORATÓRIO?
}

\author{
Iara Terra de Oliveira ${ }^{a}$, Karim Maria Chagas Zuccheratto ${ }^{b}$, Isabela Zampirollo Granado ${ }^{b}$, Paula Homem-de-Mello ${ }^{a}$ e \\ Hueder Paulo Moisés de Oliveira ${ }^{\mathrm{a}, *}$ \\ ${ }^{a}$ Centro de Ciências Naturais e Humanas, Universidade Federal do ABC, Santo André - SP, Brasil

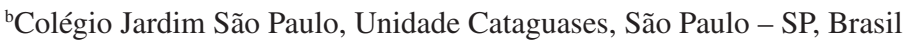

Recebido em 02/11/2017; aceito em 11/04/2018; publicado na web em 22/05/2018

\begin{abstract}
WHERE DO THE NAMES OF LABORATORY GLASSWARE COME FROM? There are many scientific discoveries and technology developments that are currently taken for granted in society as a whole, as if these had always existed. In an educational context this means that students have lost the ability to see themselves as delevopers of new technologies, assuming a role as mere users of the technologies made available by others. A contextualized appr3oach, explaining the origin of the names for the main glassware used in Chemistry classes, can make learning 3more meaningful. This approach focuses on hard work of one (or more) scientists in solving experimental problems that makes the equipment useful until the present day. Therefore we aim to humanize these creations, providing opportunities for the student to glimpse the possibility of himself contributing to the production of new equipment, techniques and knowledge through the presentation of some curious details about the invention or about the life of the scientist in question. Additionally, the images that illustrate this work, both from glassware and scientists, were made by high school students, a strategy that could also be used in classroom.
\end{abstract}

Keywords: glassware; laboratory; teaching; experimental chemistry.

\section{INTRODUÇÃO}

Nos dias atuais, tentarmos inovar nossa prática em sala de aula é de extrema importância para atrairmos o interesse dos estudantes, para que o aprendizado não seja algo cansativo ou mecânico. Nessa perspectiva, no contexto do ensino de Ciências, acreditamos que incluir uma abordagem referente à origem da designação das nomenclaturas, quando possível, seja das substâncias, elementos, unidades de medidas, instrumentos ou até de leis e teorias, possa favorecer a aprendizagem, tornando-a mais atrativa e até despertando a curiosidade científica. Silva e Cavalcante ${ }^{1}$ consideram que a curiosidade científica é um fator importante no processo de aprendizagem e que proporciona aos indivíduos maior interesse à aquisição de novos conhecimentos, pois simboliza a busca pela informação numa tentativa de estabelecer ligações de natureza explicativa com o conceito a ser aprendido.

As nomenclaturas ligadas às Ciências podem estar relacionadas à homenagem a algum cientista, etimologia da palavra ou ao seu local de origem, da sua descoberta ou fato mitológico, dentre outras proposições.

Hernánde $z^{2}$ explica as etimologias dos nomes de vários elementos químicos. Fósforo vem do latim phosphoros, que significa "portador de luz". A escolha do nome Urânio, descoberto em 1789 por Martin Heinrich Klaprothe, deu-se em homenagem ao planeta Urano, recém-descoberto pelo astrônomo inglês William Herschel em 1781. O Tório, descoberto em 1828 por Berzelius, é um exemplo de nome relacionado à mitologia, pois recebeu essa denominação em honra ao deus escandinavo do trovão e da força Thor. Já o Césio vem do latim caesium, que significa "céu azul”, atribuído por Robert Bunsen e Gustav Kirchhoff em 1860 ao elemento devido à cor característica do seu espectro de emissão. Por sua vez, o Ítrio é proveniente do nome da cidade sueca Ytterby, onde foi descoberto por Johan Gadolin em 1794. Na verdade, foi isolado mesmo por Friedrich Wohler, apenas em 1828. O que Gadolin havia separado do mineral originário de

*e-mail: hueder.paulo@ufabc.edu.br
Ytterby era o óxido de ítrio. Graças aos seus trabalhos inovadores com as terras raras, Gadolin foi homenageado com um elemento batizado com seu nome, o Gadolínio em 1880. Outro elemento que recebeu o nome em homenagem a um local é o polônio, que recebeu esse nome em homenagem ao país natal de uma das descobridoras do elemento, Marie Curie, em 1898. Assim, percebe-se que não há uma metodologia estabelecida para nomear os elementos, mas pode-se perceber uma tendência a homenagear cientistas ou os locais de descoberta, como aconteceu em 2016 quando a IUPAC (International Union of Pure and Applied Chemistry) nomeou os mais recentes elementos químicos: Nihonium em homenagem ao Japão, Moscovium a Moscou e Tennessine ao Tennessee, enquanto Oganesson foi uma homenagem ao cientista Yuri Oganessian.

Com relação a compostos químicos, Fiorucci, Soares e Cavalheiro $^{3}$ apresentaram alguns ácidos orgânicos do cotidiano e as designações para suas nomenclaturas, como no caso do ácido fórmico, que tem origem na palavra em latim formica, que significa formiga, pois o ácido pode ser obtido por destilação de arraste de vapor de amostras contendo esses insetos. O ácido acético tem seu nome derivado do latim acetum, que significa azedo e é o responsável pela acidez do vinagre. O ácido butírico deriva do latim butyrum, que significa manteiga e que proporciona um odor característico da manteiga rançosa. Por sua vez, o ácido valérico (ácido pentanoico), além de ser responsável pelo aroma do queijo roquefort, foi isolado pela primeira vez de uma raiz de valeriana, planta com efeitos terapêuticos, cujo nome deriva do latim valere, que significa saudável.

Vidal, Cheloni e Porto ${ }^{4}$ apresentaram a origem dos nomes antigos de algumas substâncias inorgânicas. Por exemplo, o nitrato de prata era chamado de cáustico lunar, em que cáustico é graças à sua propriedade de queimar e lunar devido à analogia entre a prata e o brilho da Lua. Já nitrato de chumbo(II) era conhecido como açúcar de saturno, pois tinha como propriedade o sabor adocicado e o chumbo era associado ao planeta Saturno. Dentre os planetas conhecidos na antiguidade, Saturno é o planeta que mais demora para completar sua órbita, logo mais lento e pesado, por isso associado ao elemento chumbo. Em contraposição, mercúrio, metal fluido a temperatura 
ambiente, era associado a Hermes (na mitologia grega, pois na romana era Mercúrio mesmo), o mensageiro dos deuses. ${ }^{5,6}$ Uma curiosidade é o símbolo do mercúrio: $\mathrm{Hg}$ vem do latim Hydragyrum, que em português significa prata líquida. Por outro lado, o sulfato de sódio era conhecido de sal de Glauber, em homenagem ao cientista responsável pela criação do método de obtenção, Johann R. Glauber, químico alemão. ${ }^{4}$ A IUPAC estabelece regras para se nomear os compostos, ${ }^{7}$ sejam eles orgânicos (Livro Vermelho da IUPAC) ou inorgânicos (Livro Azul da IUPAC). As recomendações da IUPAC para compostos orgânicos são apresentadas de maneira resumida na referência. ${ }^{8}$

As unidades de medida apresentam diversas origens. Como por exemplo, o metro uma das unidades de medida mais usadas, vem do grego metron, que significa medida e dá nome à ciência das medições, a metrologia. Já as unidades de temperatura, kelvin e Celsius, apresentam essas designações em homenagens aos seguintes cientistas: o físico escocês, Lord Kelvin, que desenvolveu a escala kelvin de temperatura absoluta e ao astrônomo sueco Anders Celsius, que se baseou nos pontos de fusão e ebulição da água para estabelecer a sua escala. Outro exemplo é a candela, utilizada para medir intensidade luminosa no Sistema Internacional e significa vela em latim. ${ }^{9}$ Atkins e Jones ${ }^{10}$ apresentam em sua obra alguns significados - mol, por exemplo, é uma palavra do latim que significa "pilha muito grande".

Por outro lado, Silva ${ }^{11}$ mostra que o termo entalpia foi denominado por Kamerlingh Onnes em 1909, derivada do grego talpos, que significa calor. Já uma das fórmulas mais importantes relacionadas à entropia $(\mathrm{S})$ :

$$
\mathrm{S}=\mathrm{k} \log \mathrm{W}
$$

foi proposta em 1977 pelo físico austríaco Ludwig Boltzmann, que dá nome à equação e à constante $\mathrm{k}$ (W é o número de microestados do sistema). Uma curiosidade é que essa equação encontra-se estampada no túmulo de Boltzmann em Viena. Ainda em relação a grandezas termodinâmicas, a energia de Gibbs, atrelada à entropia e à entalpia, a partir da seguinte equação:

$$
\mathrm{G}=\mathrm{H}-\mathrm{TS}
$$

é assim denominada em homenagem ao cientista americano Josiah Willard Gibbs.

Com relação à designação de alguns nomes de equipamentos usados em experimentos, o bico de Bunsen, que é um dos queimadores de gás mais utilizados no laboratório, é referenciado ao químico alemão Robert Wilhelm Bunsen, que o descreveu, pela primeira vez em detalhes no ano de 1857 numa série de artigos sobre reações fotoquímicas, juntamente com o químico britânico Henry Enfield Roscoe (Jensen, 2005). ${ }^{12} \mathrm{O}$ cadinho, usado para aquecer substâncias, segundo Lima e Silva ${ }^{13}$ vem do latim catinu, que significa tigela, bacia, cavidade. Inclusive, algumas dessas peças vêm sendo recuperadas em escavações arqueológicas, mostrando que as populações pré-coloniais detinham a tecnologia de produção da cerâmica no Brasil há pelo menos dois mil anos. ${ }^{14}$ Já tubo de ensaio é uma designação diretamente ligada à forma e função do equipamento: um objeto cilíndrico (tubo) utilizado para realizar pequenos testes (ensaio). Não se sabe ao certo seu inventor, mas a pelo menos dois renomados cientistas tem sido atribuída sua invenção: Jons Jacob Berzelius (1779-1848) e Michael Faraday (1791-1867). Berzelius descreveu um "tubo de ebulição" em um artigo de 1814, um enquanto Faraday mencionou em seu livro de 1827, Chemical Manipulation, que pequenos tubos de vidro são recipientes úteis para realizar testes de reações. Assim, aparentemente, o tubo de ensaio só passou a ser utilizado no século 19, uma vez que não são encontrados nos conjuntos de química do século 18 e, em textos dessa época, é sugerido que testes de reações sejam realizados em copos de vinho. ${ }^{15}$

Neste trabalho, propomos introduzir a nomenclatura das vidrarias nas aulas práticas de química, seja no ensino médio ou no início do ensino superior, mostrando um pouco da origem do nome, para que esse não seja um processo meramente mnemônico. Como vimos nos parágrafos anteriores e veremos um pouco mais detalhadamente para alguns equipamentos a seguir, os nomes podem ter as mais diversas origens. Conhecer essas origens pode ajudar o estudante a entender a aplicação do equipamento e mostrar o processo científico, que há muito ainda a ser aperfeiçoado e descoberto, sendo que o próprio aluno pode vir a atuar nesse processo. Segundo a concepção de Libâneo, ${ }^{16}$ o laboratório corresponde a um espaço de ensino de conhecimentos integrados e contextualizados, que também são vinculados a questões históricas e sociais.

Nessa perspectiva, o conhecimento sobre a origem dos nomes das principais vidrarias utilizadas nas aulas de Química pode tornar a aprendizagem mais significativa, uma vez que se utiliza de uma abordagem histórica. ${ }^{17-19}$ Adicionalmente, as imagens que ilustram este trabalho, tanto das vidrarias quanto dos cientistas, foram feitas por alunas do ensino médio, uma estratégia que também poderia ser utilizada particularmente visando o aprendizado daqueles alunos mais afeitos a arte. Assim, o objetivo deste trabalho é apresentar uma coletânea de vidrarias inseridas em um contexto histórico, bem como com algumas curiosidades, que possam auxiliar os educadores e educandos no processo de ensino e aprendizagem.

\section{AS DESIGNAÇÕES DOS NOMES DE ALGUMAS VIDRARIAS}

\section{Béquer}

Porto e Vanin ${ }^{20}$ explicam que "copo de Becker" (Figura 1) tem atribuição errônea ao químico e economista John J. Becher. O correto é que a palavra béquer está relacionada à bicarius no latim medieval, que significa copo. Hoje seu formato difere de um copo pela presença de um bico para realizar transferência de líquidos com mais facilidade, além de ter paredes paralelas, perpendiculares ao fundo que normalmente é plano. Mas mesmo este instrumento pode receber uma denominação relacionada a algum cientista: se for o béquer de forma alta, pode ser chamado de copo de Berzélius e, se for de forma baixa, copo de Griffin, ambos em homenagem aos cientistas que os criaram.

Neste instrumento são colocados compostos para serem aquecidos, dissolvidos ou reagidos. Para atender essa diversidade de aplicações, hoje é possível encontrar béqueres feitos com diferentes materiais, como vidro refratário ou polietileno e polipropileno, e com

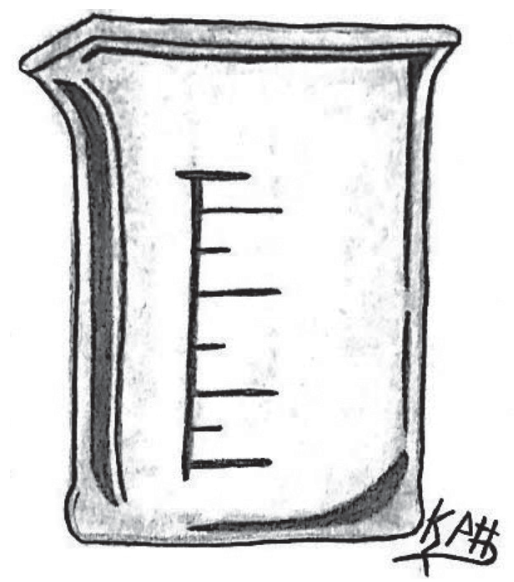

Figura 1. Representação do béquer 
diversas capacidades, desde poucos mililitros até dezenas de litros. Um erro bastante comum de iniciantes em atividades experimentais é a utilização do béquer como instrumento de medida de volume. É importante discutir com os alunos a questão da precisão em medidas volumétricas, mostrando que a escala que muitos béqueres apresentam é apenas uma indicação de capacidade do instrumento.

\section{Erlenmeyer}

O erlenmeyer (Figura 2) tem nome referenciado ao sobrenome do seu criador, o químico alemão Richard August Carl Emil Erlenmeyer (1825-1909, Figura 3). Era filho de um pastor evangélico e desde a adolescência queria ser médico. Porém, com as palestras de Liebeg (cientista alemão considerado o pai da química orgânica), ficou tão encantado que trocou a medicina pela química. ${ }^{21} \mathrm{O}$ desenho do instrumento foi feito pela primeira vez pelo cientista em 1850, mas somente em 1860 publicou um artigo sobre o equipamento, embora naquele momento já estivesse sendo produzido e vendido. ${ }^{22} \mathrm{O}$ cientista foi o primeiro a enunciar que o carbono poderia fazer ligação simples, dupla e tripla. ${ }^{19}$

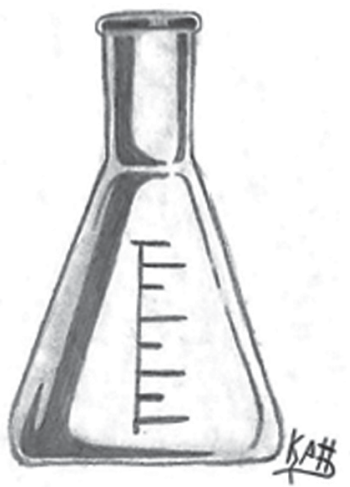

Figura 2. Representação do erlenmeyer

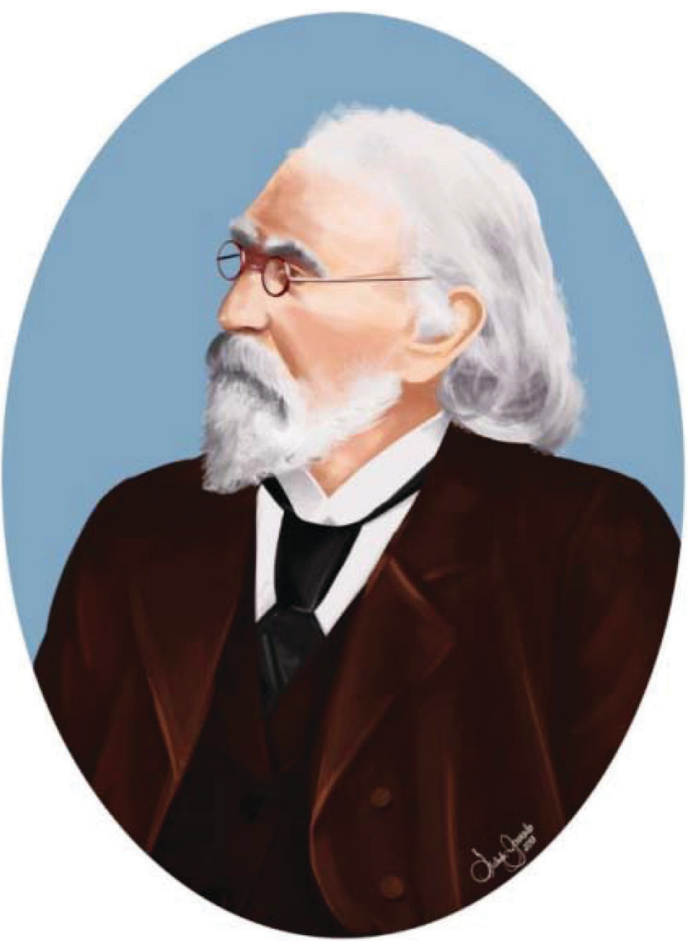

Figura 3. Imagem de Richard August Carl Emil Erlenmeyer adaptada da referência 23
No laboratório, existem diversas variantes do instrumento com amplas formas e, dependendo da aplicação, com diferentes tipos de tampas e com volumes que vão de 25 a $5000 \mathrm{~mL}$. Originalmente eram feitos de vidro, mas atualmente podem ser produzidos em vidro borossilicato ou Duranglas, e também serem confeccionados com policarbonato, polietileno tereftalato, polipropileno e teflon. Além de apresentar as mesmas funções do béquer, graças ao seu aspecto afunilado, o erlenmeyer é utilizado na titulação, pois diminui o contato do meio reacional com o $\mathrm{O}_{2}$ atmosférico no caso de certas reações em que isso não é desejado, além de facilitar a agitação, evitando perda de amostra.

\section{Balão Kitasato}

Pode ser chamado de Balão Kitasato ou mais simplesmente Kitassato ou Kitasato. É constituído de um vidro espesso e possui duas saídas (Figura 4). Esta peça deve o seu nome em homeangem a Shibasaburo Kitasato (1852-1931, físico e médico japonês, ${ }^{24}$ Figura 5). Foi um dos cientistas japoneses mais prestigiados devido às suas importantes contribuições no desenvolvimento científico:

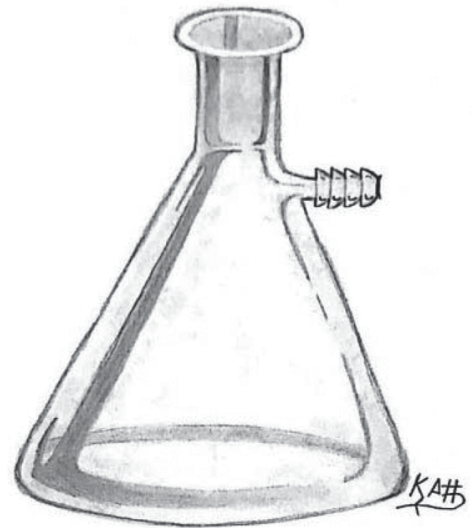

Figura 4. Imagem do balão de Kitasato

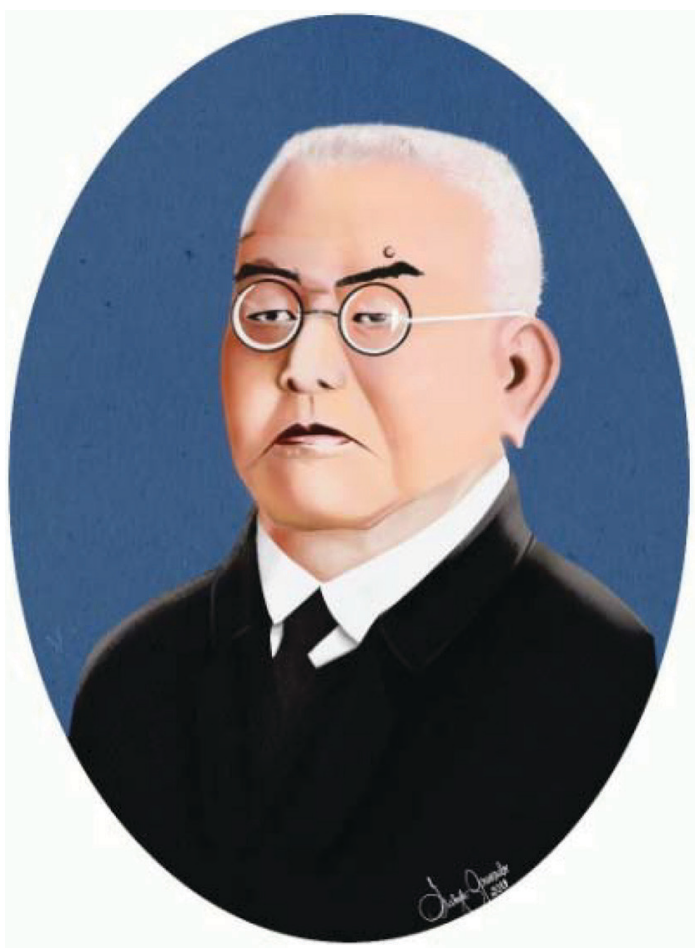

Figura 5. Imagem de Shibasaburo Kitasato adaptada da referência 27 
descobriu uma antitoxina para combater a bactéria que causa o tétano. ${ }^{25}$

Também conhecido como balão de vácuo, filtro de balão, balão de lado, é um erlenmeyer com um braço que consiste de um tubo de vidro curto e projetado cerca de um centímetro de seu pescoço. $\mathrm{O}$ tubo efetivamente atua como um adaptador no qual uma mangueira flexível pode ser anexada.

É normalmente usado em conjunto com o funil de Büchner (veremos a origem do nome a seguir) em filtrações (sob sucção) a vácuo ou pressão reduzida. Esse método é mais rápido e eficiente que uma filtração comum. Para montar o sistema de filtração a vácuo, à passagem superior é adicionado o funil de Büchner, e uma mangueira é colocada na saída lateral do recipiente. Essa mangueira pode ser anexada a uma bomba de vácuo ou a uma torneira, pois ao ser acionada, a água em movimento gera uma diferença de pressão. Uma ótima revisão sobre processos de filtração pode ser encontrada na literatura. ${ }^{26}$

\section{Funil de Büchner}

Muitos acreditam que o nome deste funil (Figura 6) seja em homenagem ao Prêmio Nobel Eduard Buchner (1860-1917), bioquímico alemão e ganhador do Prêmio Nobel de Química em 1907, por ter demonstrado a fermentação dos açúcares. Mas na verdade é em homenagem ao químico industrial alemão Ernst Büchner (18501925), Figura 7.28,29

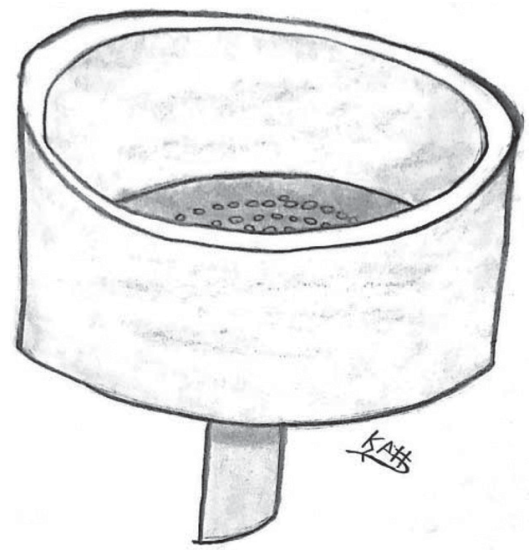

Figura 6. Imagem do funil de Büchner

Este é o funil que é acoplado à entrada superior do kitassato para fazer filtração a vácuo. Por isso, deve ser feito em material bastante resistente, como porcelana ou vidro, mas há também aqueles feitos em plástico. Sobre sua base, que é toda perfurada, coloca-se o filtro de papel (de diâmetro igual à base do funil e molhado com o solvente da solução que se pretende filtrar) que reterá o sólido durante a filtração conforme Figura 8.

\section{Funil de Hirsch}

Apresenta mesma finalidade que o funil de Büchner no processo de filtração à vácuo. A principal diferença de ambos é referente ao volume da amostra usada. O funil de Hirsch (Figura 9) é usado na separação de volumes menores, tipicamente de 1 a $10 \mathrm{~mL}$ (mas há funis de Hirsch para volumes maiores). Outra diferença é que no funil de Hirsch pode haver placa filtrante de vidro sinterizado (um vidro poroso, obtido a partir do aquecimento de partículas de vidro) no lugar da base com furos presente no Büchner. $23,26,32$

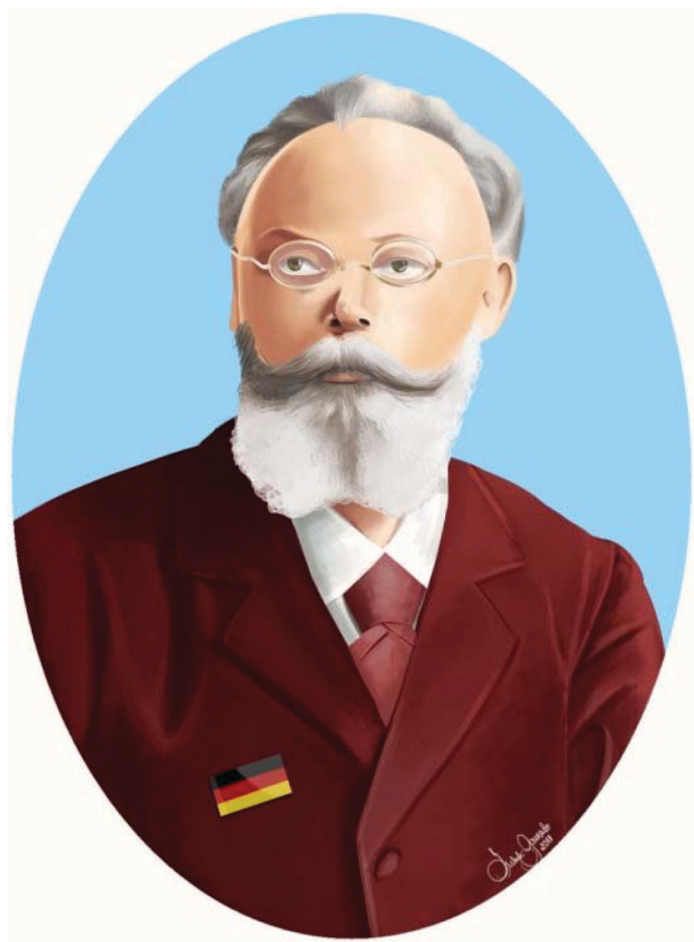

Figura 7. Imagem de Ernst Büchner adaptada das referências 30 e 31 com permissão da Royal Society of Chemistry

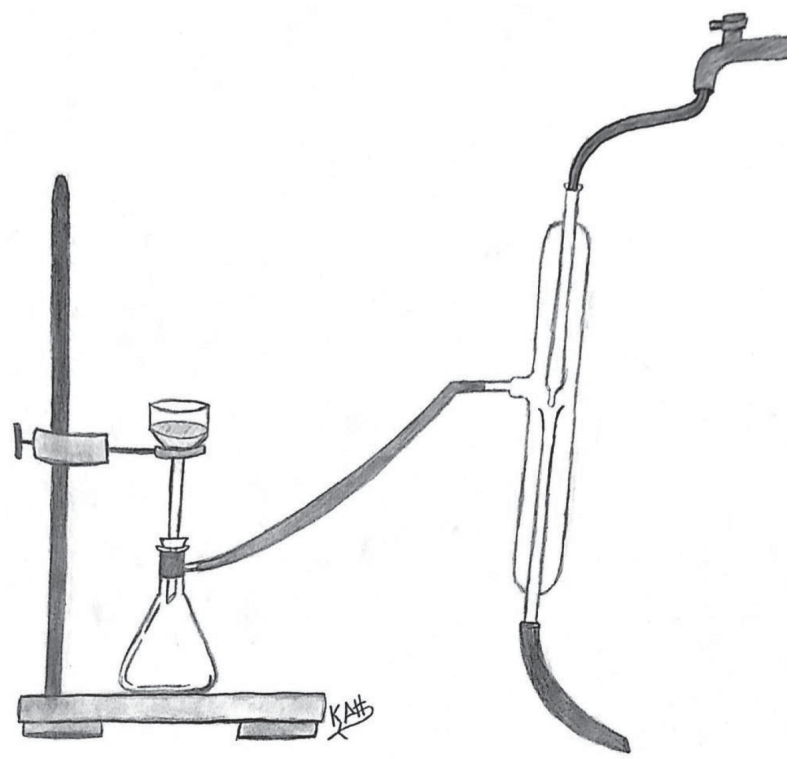

Figura 8. Imagem do sistema de filtração a vácuo

A denominação deste funil foi feita em homenagem ao idealizador do equipamento, o químico polonês Robert Hirsch (1856-1913) (Figura 10). Após terminar seu doutorado em Strasbourg com Rudolf Fittig, um dos mais proeminentes químicos orgânicos da época, Hirsch passou a trabalhar na crescente indústria de corantes nos arredores na Alemanha e depois na Inglaterra, realizando pesquisas inovadoras. Em 1888 publicou a pequena nota sobre o instrumento que imortalizou seu nome. ${ }^{27}$

\section{Bureta}

Era conhecida antigamente pelo nome de cilindro graduado (Figura 10) e foi primeiramente desenvolvida pelo farmacêutico 


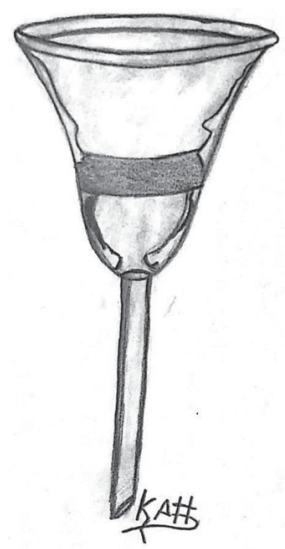

Figura 9. Ilustração do funil de Hirsch

francês François Antoine Henri Descroizilles (1751-1825) no ano de 1791, Figura 11. Este cientista dedicou maior parte da sua vida a atividades industriais e aperfeiçoamento de equipamentos que realizam análises quantitativas de amostras químicas. É considerado o precursor das análises volumétricas. A bureta, instrumento cilíndrico graduado de vidro (Figura 11), permitiu medir concentrações com bastante precisão através da técnica conhecida como titulação. $\mathrm{O}$ artigo de Terra e Rossi ${ }^{33}$ traz um belo histórico sobre as análises volumétricas.

Um fato curioso sobre a vida de Descroizilles é que, em 1801, foi salvo pelo seu assistente de um incêndio no laboratório causado pelo contato do elemento químico fósforo com água, que ateou fogo a livros e papéis. $\mathrm{O}$ frasco que estava armazenado o fósforo estava envolvido por papel, que absorveu água e fez com que essa amostra entrasse em contato com ar, provocando as chamas. ${ }^{34}$

O químico e físico francês Joseph Louis Gay-Lussac (1778-1850) desenvolveu uma versão melhorada, que incluiu um braço lateral. Esse importante cientista francês, reconhecido pelas suas contribuições à lei dos gases, cunhou a expressão "pipeta" e "bureta" sobre a padronização de soluções de anil. Pipeta deriva de pipe, "flauta" em francês,

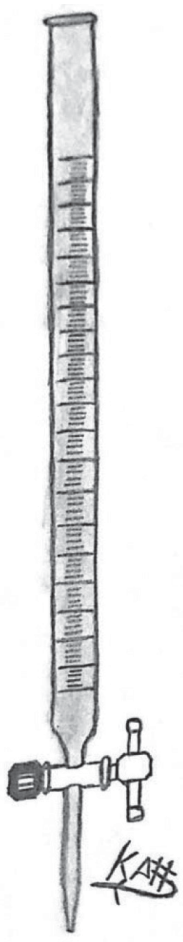

Figura 10. Imagem da bureta

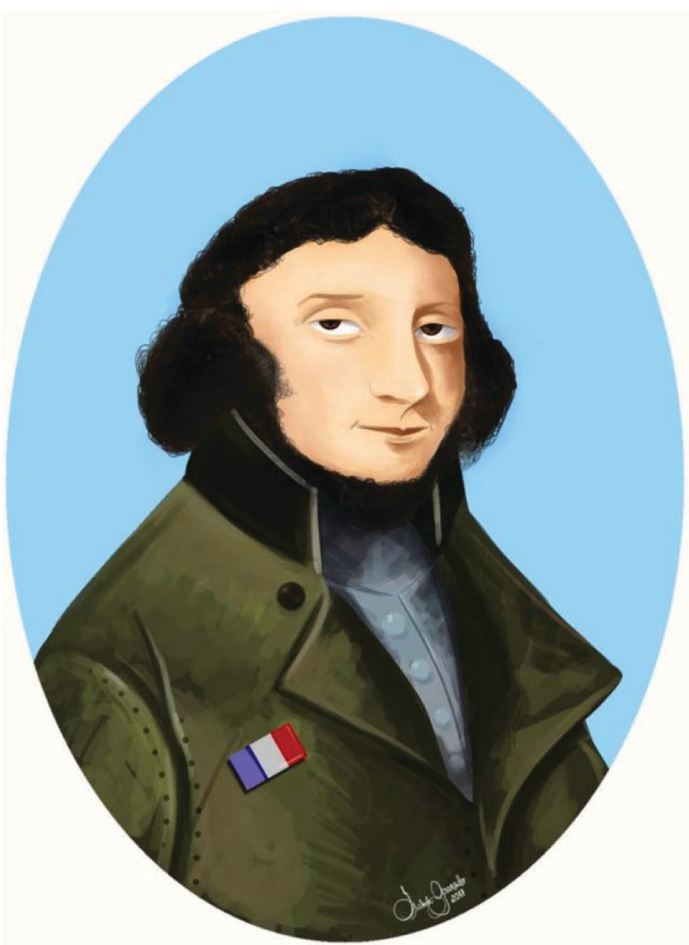

Figura 11. Imagem de François Antoine Henri Descroizilles adaptada das referências 38 e 39 com permissão da Division of Chemical Education of the American Chemical Society

enquanto bureta vem do francês antigo buk, que significa "cântaro, pequena garrafa". Outra curiosidade é que, em 1808, juntamente com o cientista francês Louis Jacques Thénard (1777-1857), Gay-Lussac isolou o potássio, extraindo-o do carbonato de potássio (conhecido como potassa). ${ }^{35}$ Por volta de 1845 , Étienne Ossian Henry construiu um instrumento que se parece mais com o instrumento atual, de vidro e com torneira (de cobre) para o controle do fluxo da solução de titulante e, por isso, muitas vezes ele é considerado o criador da bureta, já que o instrumento de Descroizilles mais lembrava uma proveta, embora fosse utilizado em titulações. Dez anos depois, Karl Friedrich Mohr aperfeiçoou a bureta de Henry ao colocar uma pinça no lugar da frágil torneira e fazer uma escala graduada, inspiração para as buretas utilizadas até hoje..$^{33,36,37}$

\section{Tubo de Thiele}

O tubo de Thiele (Figura 12) recebe seu nome em homenagem ao químico polonês Friedrich Karl Johannes Thiele (1865-1918) (Figura 13). Na infância seus brinquedos favoritos eram balões e retortas e seu interesse pela ciência foi estimulado pelos pais.

O tubo é um instrumento de vidro usado na determinação da temperatura de fusão de uma substância. Esta é uma propriedade muito importante, característica de cada substância. Logo, esse tipo de medida pode ser de grande valia, por exemplo, em uma síntese para verificar se o produto obtido encontra-se puro ou contém impurezas, como reagentes ou subprodutos. Para tanto, coloca-se uma amostra da substância em um tubo capilar, que é preso a um termômetro. Esse sistema é colocado dentro do tubo Thiele preenchido com óleo. Este tubo se parece muito com um tubo de ensaio, mas com um braço lateral. Este braço é que permite que, durante o aquecimento do óleo, ocorram as correntes de convecção, muito importantes para fazer com que a transferência de calor seja a mais uniforme e rápida possível. Procedimento parecido pode ser utilizado para a determinação do ponto de ebulição. ${ }^{40,41}$ 


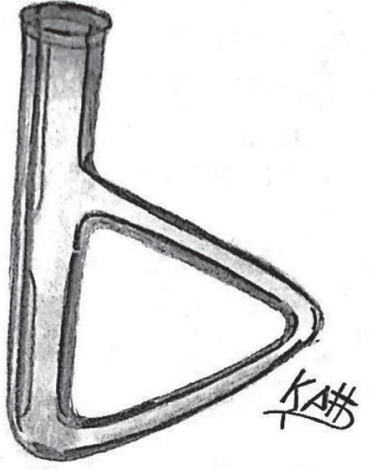

Figura 12. Imagem do tubo de Thiele

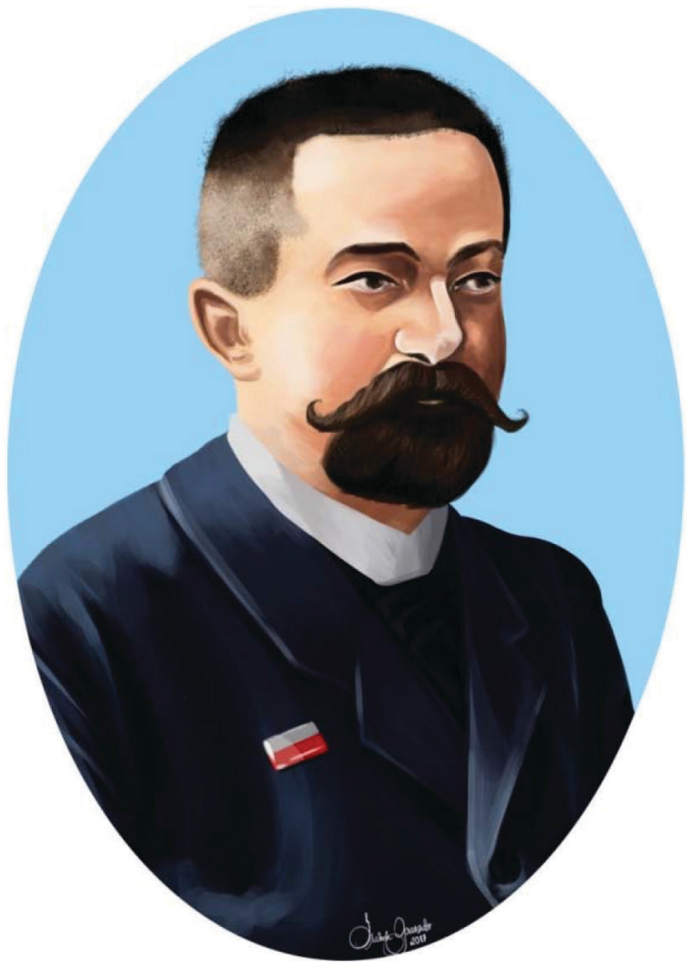

Figura 13. Imagem de Friedrich Thiele adaptada da referência 42

\section{Placa de Petri}

Também chamado de "prato de cultura de células" é um material de vidro raso ou cilíndrico de plástico com tampa utilizada (Figura 14) para culturas de células e microrganismos. Seu nome foi dado em homenagem ao seu inventor, o médico alemão Julius Richard Petri (1852-1921) (Figura 15), que a inventou quando trabalhava como auxiliar de Robert Koch (1843-1910) (Figura 16). Koch é um dos fundadores da microbiologia, descobridor da bactéria causadora da tuberculose (o Bacilo de Koch) e considerado pai da bacteriologia moderna. ${ }^{43}$ Koch começou suas pesquisas científicas em sua própria casa, nas horas vagas em que não estava atuando como médico na pequena cidade de Wolsztyn, na Polônia. Apesar de estar nesse ambiente isolado, longe dos grandes centros científicos, Koch fez descobertas revolucionárias. Estudou o antrax e provou que a doença, na época uma doença comum nos animais, era causada por esse microrganismo e mais, demonstrou que mesmo microrganismos crescidos em laboratório poderiam causar a doença. Por conta dessas descobertas, em 1880, Koch foi convidado a trabalhar em Berlim. Com mais estrutura laboratorial e contando com a colaboração de diversos cientistas, Koch

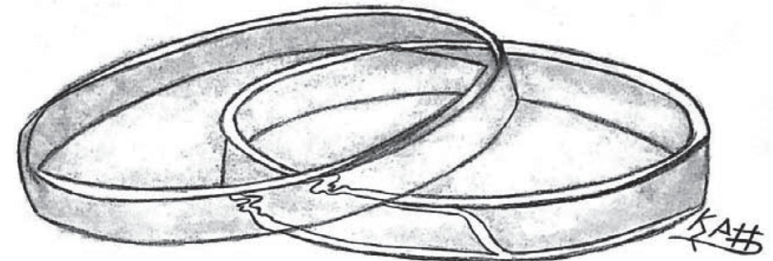

Figura 14. Imagem da placa de Petri

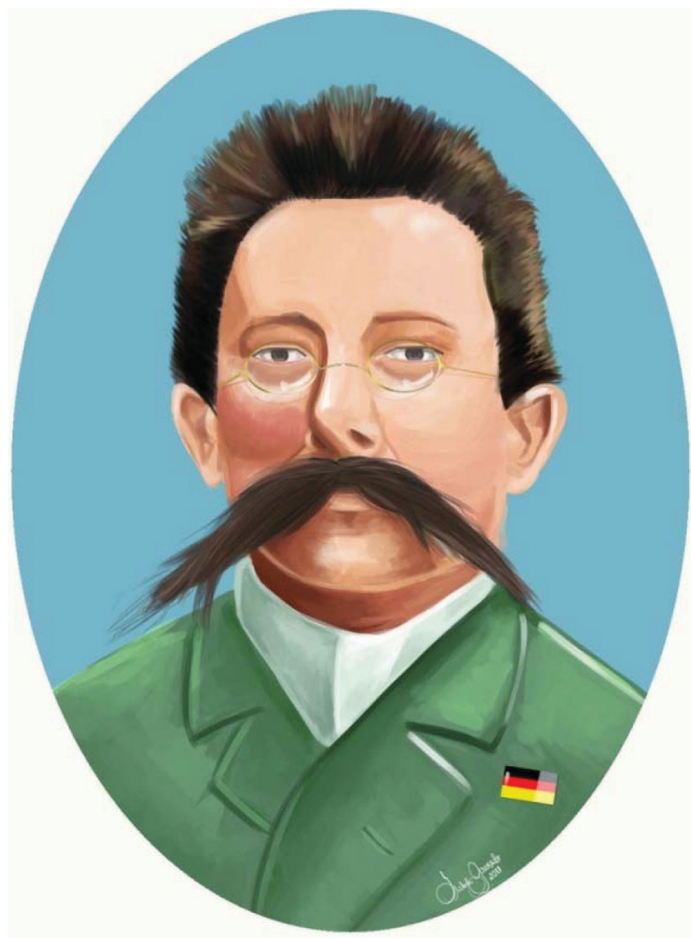

Figura 15. Imagem de Julius Petri adaptada da referência 47

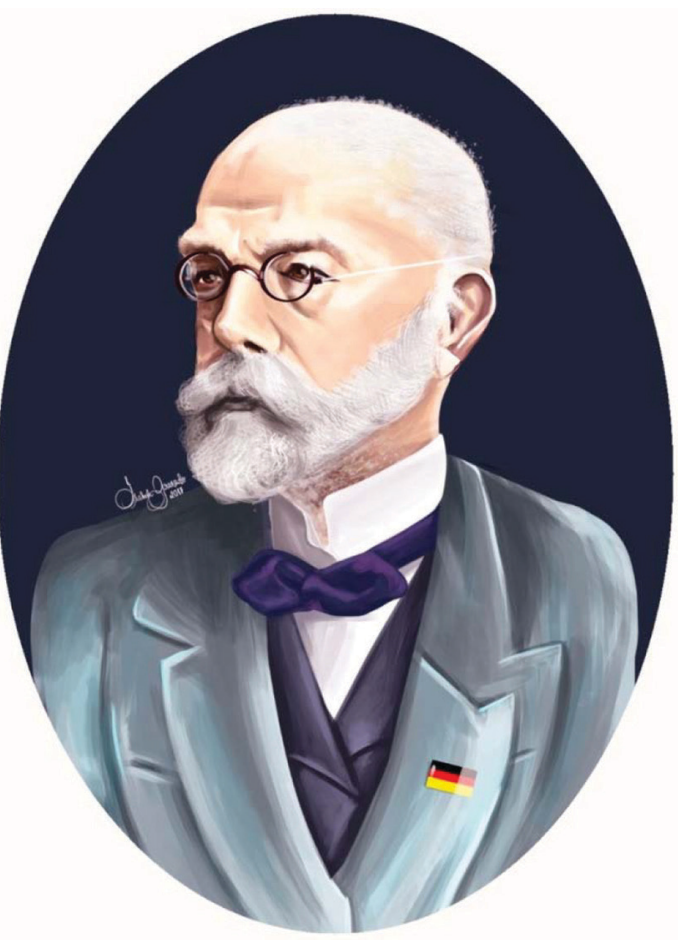

Figura 16. Imagem de Robert Koch adaptada das referências 44 e 48 
continuou aperfeiçoando o que hoje chamamos de microbiologia, ou a "arte" de identificar microrganismos e a estabelecer correlações que permitam atribuir uma dada doença a um microrganismo específico (Postulados de Koch). Desenvolveu diversas técnicas para esses estudos, utilizando um meio sólido para cultivar os microrganismos no instrumento que veio a se chamar Placa de Petri. ${ }^{44,45}$

Este instrumento foi muito importante para os avanços da microbiologia. Antes dele, o caldo endurecido com gelatina (ou ágar) para crescer e imobilizar seus organismos, era despejado em lâminas de microscópio ou em copos de vinho protegidos com cúpulas para evitar contaminação. Quando Petri passou a participar do grupo de Koch, ele propôs a utilização de um prato com paredes baixas para conter o caldo e um outro prato, de diâmetro ligeiramente maior, para ser usado como tampa. Com isso, passou a ser possível visualizar o crescimento das colônias. ${ }^{43,44}$

No entanto, há uma controvérsia se o instrumento foi mesmo criado por Petri. Seu trabalho foi publicado em 1887, enquanto os romenos Andre Cornil and Victor Babes publicaram um livro sobre bacteriologia em 1885 no qual descreveram um equipamento semelhante, inclusive com ilustrações. Assim, provavelmente o real inventor da placa de Petri não foi Petri, mas ele e Koch foram os responsáveis pela sua ampla divulgação e estabelecimento das técnicas para utilizá-la. ${ }^{43,44}$

Hoje existem placas de Petri em todos os laboratórios para o estudo dos mais diversos fenômenos, desde o crescimento de fungos e bactérias ao estudo de reações químicas oscilantes. ${ }^{43,44}$ Placas de Petri de vidro podem ser reutilizadas por esterilização (por exemplo, em autoclave ou por aquecimento do ar seco em um forno quente a $160{ }^{\circ} \mathrm{C}$ durante uma hora). Para experimentos em que a contaminação cruzada de um experimento para o outro pode se tornar um problema, placas de plástico devem ser utilizadas e descartadas após o uso. As placas modernas possuem anéis sobre as tampas e as bases que lhes permitem serem empilhadas de forma a não escorregar uma sobre a outra. ${ }^{46}$

\section{Vidro de Relógio}

É uma peça circular (Figura 17), ligeiramente côncava de vidro utilizada como uma superfície de evaporação de um líquido, para pesar sólidos ou como uma cobertura para um recipiente aberto para evitar a introdução de poeira. Esse material não pode ser aquecido diretamente. São assim chamados porque são idênticos aos empregados para o vidro frontal dos antigos relógios de bolso. ${ }^{35}$

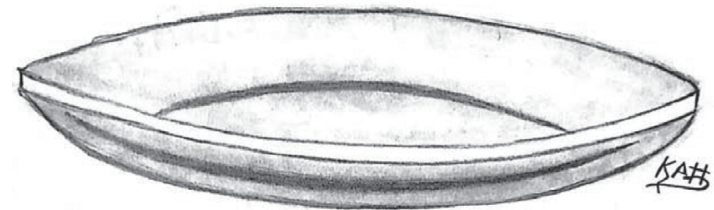

Figura 17. Imagem do vidro de relógio

\section{Viscosímetro de Ostwald}

É um aparato geralmente de vidro usado para medir a viscosidade de líquidos, consistindo de um tubo em forma de U (conforme Figura 18), que possui uma seção na posição vertical com abertura precisa e estreita. O equipamento consta de dois bulbos, como pode ser observado na figura, em que um deles aparece na parte superior do lado esquerdo e outro mais baixo do lado direito. ${ }^{49}$ Seu nome é referenciado a Friederich Wilhelm Ostwald (1853-1932), químico alemão e idealizador do instrumento, (Figura 19). Seus estudos iam além da química, interessava-se também pela física, mostrando a importância do conhecimento matemático para interpretação das diferentes situações científicas. Inclusive o químico sueco Arrhenius (1859-1927) foi colaborador de Ostwald e realizou centenas de experimentos com o equipamento do colega para compreender o efeito da dissolução de substâncias em água a partir das medidas de viscosidade. ${ }^{50}$

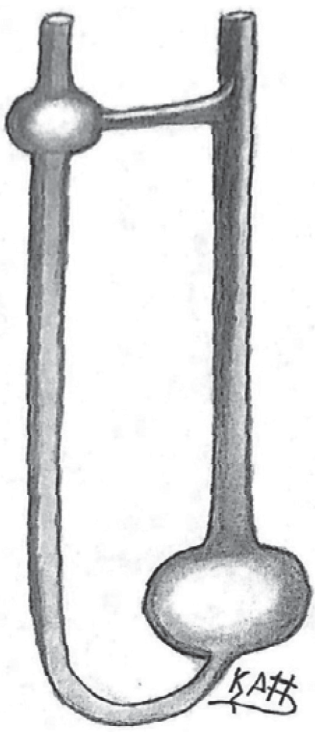

Figura 18. Imagem do viscosímetro de Ostwald

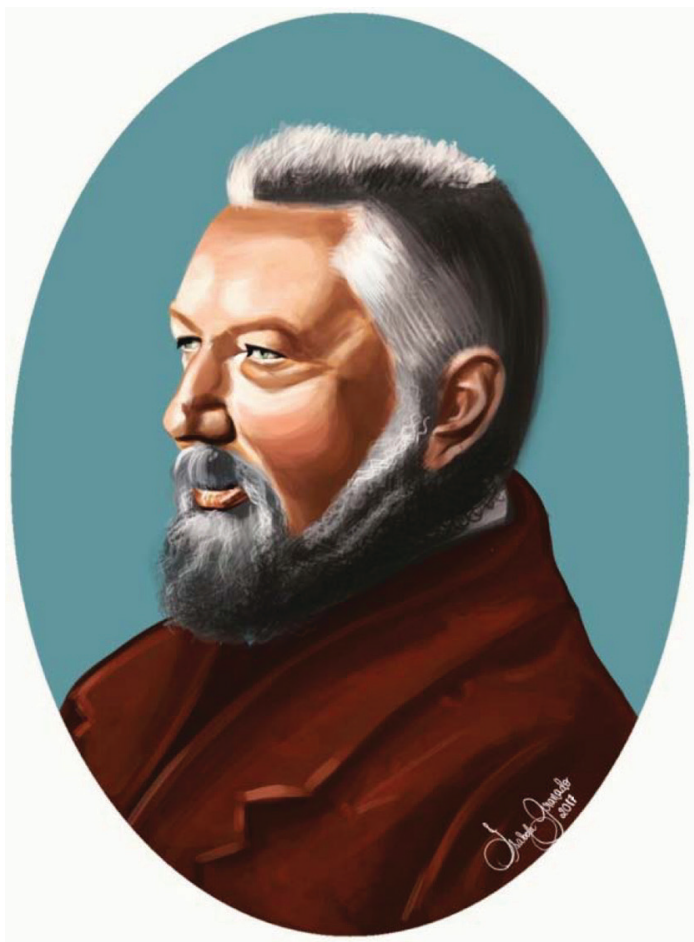

Figura 19. Imagem de Friederich Wilhelm Ostwald adaptada das referências 49 e 50

\section{Extrator de Soxhlet}

O extrator de Soxhlet é um formado de um balão, que fica na parte inferior, um condensador na parte superior e um reservatório que fica entre essas duas estruturas (Figura 20). Atua no processo de extração entre sólido e líquido, no qual o solvente é colocado no balão e aquecido até a ebulição. Seu vapor, quando atinge o condensador, volta a se transformar em líquido. As gotículas resultantes dessa transformação alcançam o papel de filtro e enchem o reservatório até 
o nível do tubo lateral, que transportam o solvente de volta para o balão juntamente com as substâncias contidas no papel de filtro, que são solúveis. O ciclo é restabelecido até a obtenção do composto final.

Este equipamento foi criado em 1879 pelo químico alemão Franz Ritter Von Soxhlet (1848-1926), (Figura 21). Graduado em Leipzig, lá também obteve seu título de doutor. Em 1879, tornou-se professor de Fisologia Animal e Latícinios no Colégio Agrícola de Munique, ficando lá até sua morte. Dedicou-se maior parte da sua carreira acadêmica à investigação das propriedades do leite. Foi o primeiro cientista a descrever sobre a lactose e separar as principais proteínas do leite. Além disso, em 1886, esse cientista alemão foi o primeiro a propor um processo de pasteurização do leite. ${ }^{51}$ Atualmente existem novos tipos de extratores no mercado, porém ainda muitos desses são variações do modelo proposto por Soxhlet. ${ }^{52,53}$

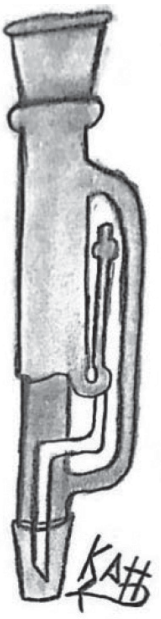

Figura 20. Imagem do extrator de Soxhlett

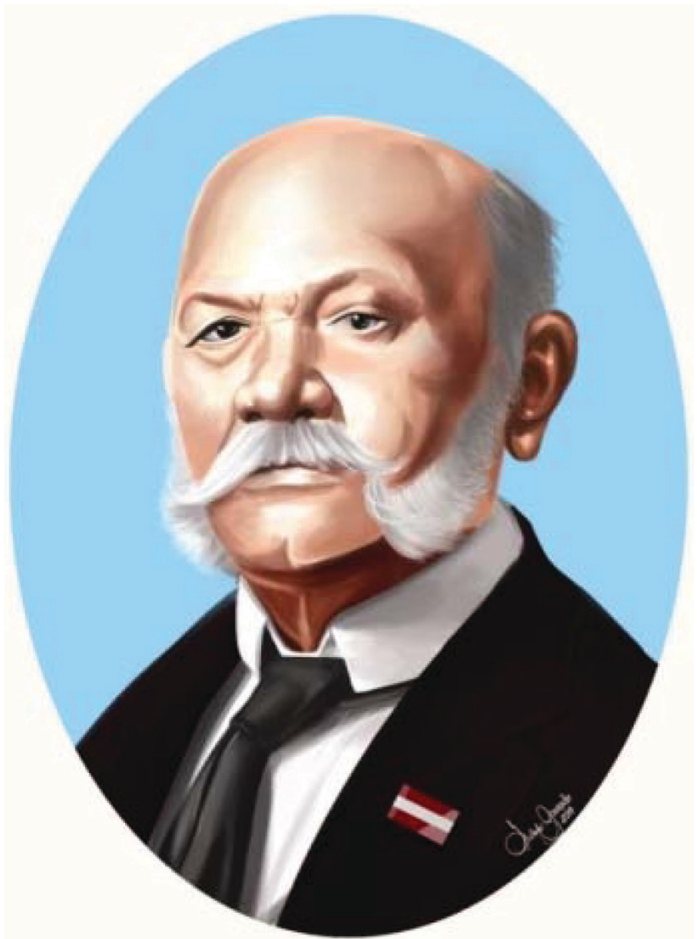

Figura 21. Imagem de Franz Ritter Von Soxhlet adaptada da referência 54

\section{POSSÍVEIS ABORDAGENS EM SALA DE AULA}

Nas aulas experimentais, é importante que os alunos utilizem os equipamentos mais adequados a cada etapa do experimento, inclusive por questões de segurança. No entanto, nem sempre é possível associar nome à função, pois como apenas demonstrado, as origens dos nomes são as mais diversas e, em muitos casos, homenagens a cientistas. Nossa experiência indica que os alunos chegam ao ensino superior conhecendo pouquíssimas vidrarias, geralmente apenas o tubo de ensaio e o béquer, e acreditam que o béquer possa ser utilizado como instrumento de medida de volume. Cabe apenas destacar que são exceções os alunos que passam por ensino médio técnico em química, que possuem um repertório sobre práticas laboratoriais inerente à sua formação técnica.

Conversamos então com alguns colegas, professores ou técnicos do Ensino Fundamental II e Ensino Médio sobre o ensino das vidrarias. Segundo o depoimento de um colega professor do ensino básico:

É comum no ensino fundamental ( $9^{\circ}$ ano) e na primeira série do ensino médio, a prática que envolve a apresentação de alguns instrumentos e principais vidrarias de forma a desenvolver nos alunos a destreza no manejo dos mesmos. $O$ manuseio correto desses materiais acrescenta às aulas um rigor científico aos resultados obtidos. Apresentar os materiais, suas origens e o significado de seus nomes, estimula o aluno a pensar, a aguçar a curiosidade científica e torna seu aprendizado mais integral.

No caso específico das vidrarias, Melchior e Boeck ${ }^{55}$ apresentaram uma proposta de metodologia de ensino a estudantes de um colégio técnico e também da Educação Básica na modalidade de Jovens e Adultos, que tinha como uma das finalidades reconhecer e manusear com segurança as vidrarias de laboratório. Richter et al..$^{56}$ desenvolveram um jogo da memória sobre instrumentos de laboratório, com alunos do sexto ano do Ensino Fundamental II de uma escola pública do Estado do Rio Grande do Sul.

A inspiração para este trabalho foram questionamentos dos nossos alunos em relação às designações das vidrarias, como "Bureta... de onde vem esse nome?”. Um dos colegas professores menciona que:

[...] nossos alunos têm uma visão (própria) de que na Química, tudo o que é necessário para o laboratório, já vem pronto [...] desde a antiguidade. [...] o conhecimento químico não vem pronto, vem da necessidade de, por vezes, criar, reinventar vidrarias como as apresentadas, para executar as análises que os cientistas tinham a necessidade de concluir ou de dar continuidade a um processo analítico, por exemplo, na época em que as desenvolveram; [é interessante mostrar] para os alunos que a Química não é dogmática e nem impessoal, mas sim em constante evolução e que há pessoas que criaram as vidrarias que eles (os alunos) usam em laboratório ou vêem em livros didáticos.

Ainda, uma professora destacou que:

Em 25 anos de ensino de Química, fui muitas vezes questionada por alguns alunos sobre a origem do nome de certos equipamentos de laboratório. Creio que o conhecimento sobre o nome das vidrarias, além de despertar o interesse e a curiosidade dos alunos, mostra que o cotidiano das Ciências está intimamente associado a um dado momento histórico e a sociedade que o circunda. Demonstra assim que o fazer ciência não é algo desvinculado de contexto, proporcionando ao estudante uma visão mais real do mundo científico.

Outro colega reforça que "humanizar a ciência, apresentando as 
facetas de alguns importantes expoentes, é de suma importância para exemplificar aos nossos educandos que as disciplinas de ciências não são descoladas de nossa realidade, sendo exercidas por seres tão "humanos" quanto eles". Um dos professores levantou ainda um o seguinte aspecto:

A ciência [pode ser apresentada] como algo pronto e definitivo, favorecendo um ensino de ciências descontextualizado e indiscutível. [Mas na verdade] é um processo em construção dinâmico, que vai se concretizando à medida que as necessidades são concebidas pela sociedade. Saber a "origem das coisas" é muito importante porque retrata os costumes de uma sociedade, resgata a história inserida nesse contexto, valoriza o saber de diferentes povos e contribui para o avanço da ciência e da tecnologia. Dessa forma, possibilita aos estudantes o desenvolvimento de um espírito crítico, questionador, resultando na construção dos conhecimentos científicos

Assim, uma estratégia interessante seria pedir que os alunos procurassem a origem dos nomes, algumas vezes do latim ou grego, às vezes do francês, e assim além de entender o nome do equipamento, muitas vezes o aluno pode entender sua função. No caso das vidrarias que recebem nome em homenagem ao seu inventor, seria interessante pedir ao aluno levantar os assuntos que o cientista estudava, para verificar o porquê da invenção. Nesse sentido, poderiam ser indicados livros e artigos para embasar essa pesquisa. Vale a pena destacar o conjunto de artigos escritos por Andrea Sella intitulados Classic Kit, uma iniciativa da Royal Society of Chemistry (também disponíveis via twitter), ${ }^{57}$ assim como referenciais em português citados ao longo deste trabalho.

Tivemos a oportunidade de utilizar outra abordagem ainda: pedir que alunos desenhassem as vidrarias ou seus inventores. As imagens que ilustram este trabalho são de autoria das alunas do Ensino Médio Isabela Zampirollo Granado e Karim Maria Chagas Zuccheratto (imagens dos cientistas elaboradas por I. Z. G. com o software Adobe Photoshop com mesa digitalizadora Wacon e imagens das vidrarias elaboradas por K. M. C. Z em grafite sobre sulfite). Segundo Francisco Junior:

O ser humano tem, além da capacidade de cognição, as dimensões de emoção e atitudes. Historicamente as escolas só levam em conta a cognição, o que é um erro. Então a arte pode ser utilizada como uma ferramenta para emocionar os alunos e despertar um estímulo de resposta, é um facilitador do processo de aprendizado ${ }^{58}$

De fato, com essas alunas, a utilização do desenho parece ter despertado interesse. Uma das alunas afirma que:

A participação nesse artigo foi uma experiência incrivel para o meu aprendizado, tanto em relação a desenho de retratos, já que acabei aprimorando e conhecendo novas técnicas, quanto em relação ao conhecimento de química. É muito interessante finalmente conhecer os cientistas que nomeiam as vidrarias tanto utilizadas por nós nas aulas de química, mas que nunca foram devidamente explicadas além de seu uso prático. Saber curiosidades científicas ajuda muito para nós, alunos, associarmos o conteúdo - fica muito mais fácil lembrar sem precisar decorar - e com esse assunto não foi diferente.

Já a outra aluna menciona que “
A experiência de fazer os desenhos dos frascos [é] muito interessante, pois nunca tinha desenhado algo naquele estilo, além de descobrir alguns nomes que eu não sabia. [...] concordo com a ideia de passar aos alunos a origem dos nomes de cada instrumento, já que essa informação ajuda a aumentar tanto o interesse quanto o próprio entendimento da ligação do objeto com a forma de chamá-lo, portanto, gostei muito de ajudar com meus desenhos e espero ter contribuído para a conclusão do trabalho como um todo.

Desses depoimentos fica claro o interesse em também contribuir para a aprendizagem dos colegas. Assim, uma estratégia que poderia ser adotada em sala de aula seria pedir que cada aluno estudasse uma vidraria, descobrisse informações e fatos curiosos, e fizesse uma breve apresentação aos demais, seja oral, escrita, ou qualquer outra mídia.

\section{CONSIDERAÇÕES FINAIS}

Neste trabalho procuramos apresentar a justificativa e o contexto para a denominação de algumas vidrarias de laboratório, compilando informações de diferentes referências e ilustrando com desenhos feitos por alunas do ensino médio.

Buscamos essa abordagem no sentido de sensibilizar os estudantes que esses equipamentos são fruto do trabalho de um ou mais cientistas, em resposta a necessidades de sua época, mas que fazem com que esses equipamentos sejam empregados ainda hoje. A apresentação de alguns detalhes curiosos sobre a invenção ou sobre a vida do cientista humanizam essas criações e podem permitir que o estudante vislumbre a possibilidade de ele mesmo passar a contribuir com a produção de novos equipamentos, técnicas e conhecimento.

\section{AGRADECIMENTOS}

Aos alunos, professores e técnicos do Colégio Jardim SP, Unidade Cataguases, da cidade de São Paulo (SP). I. T. O. agradece à Fundação Universidade Federal do ABC pela bolsa de doutorado. P. H. M. agradece ao $\mathrm{CNPq}$ pelo projeto universal e bolsa de produtividade. H. P. M. O. agradece ao CNPq pelo auxílio recebido (Edital Universal 474019/2012-8). Os autores agradecem ao gerador de nuvens de palavras WordClouds (https://www.wordclouds.com).

\section{REFERÊNCIAS}

1. Silva, P. B.; Cavalcante, P. S.; Enseñanza de las Ciencias 2009, 2745.

2. Hernández, J.; Pliegos de Yuste 2006, 4, 57.

3. Fiorucci, A. R.; Soares, M. H. F. B.; Cavalheiro, E. T. G.; Quim. Nova Esc. 2002, 15, 6.

4. Vidal, P. H. O.; Cheloni, F. O.; Porto, P. A.; Quim. Nova Esc. 2007, 26, 29.

5. http://astroespaco.xpg.uol.com.br/Saturno.html, acessada em Abril 2018.

6. https://jaircorp.wordpress.com/category/saturno/, acessada em Abril 2018.

7. https://iupac.org/what-we-do/books/color-books/, acessada em Abril 2018.

8. Rodrigues, J. A. R.; Quim. Nova Esc. 2001, 13, 22.

9. https://ipemsp.wordpress.com/2010/07/26/a-origem-dos-nomes-dasunidades-de-medir/, acessada em Abril 2018.

10. Atkins, P. W.; Jones, L.; Princípios de Química: Questionando a Vida Moderna e o Meio Ambiente, $3^{\mathrm{a}}$ ed., Bookman: Porto Alegre, 2006.

11. Silva, J. L. P. B.; Quim. Nova Esc. 2005, 22, 22.

12. Jensen, W. B.; J. Chem. Educ. 2005, 82, 518.

13. Lima, T. A.; Silva, M. N.; Anais do Museu Paulista 2001, 8, 9. 
14. Milheira, R. G.; Marin, D. A.; Ortiz, S. F.; Coradi, S.; Motta, P.; Von Der Mühlen, C.; Revista Memória em Rede 2014, 10, 1.

15. http://americanhistory.si.edu/collections/search/object/nmah_1343038, acessada em Janeiro 2018.

16. Libâneo, J. C. Em Temas de Pedagogia: Diálogos entre Didática e Currículo; Libâneo, J. C., Alves, N., eds.; Corte: São Paulo, 2012.

17. Pires, R. O.; Abreu, T. C.; Messeder, J. C.; Ciência em Tela 2010, 3, 1.

18. Zucco, C.; Pessine, F. B. T.; Andrade, J. B.; Quim. Nova 1999, 22, 454.

19. Azevedo Neta, S. L.; Messeder, J. C.; Caderno de Resumos do IV Encontro Nacional de Ensino de Ciências da Saúde e do Ambiente, Niterói, Brasil, 2014.

20. Porto, P. A; Vanin, J. A.; Quim. Nova 1993, 16, 69.

21. https://www.chemistryworld.com/opinion/classic-kit-erlenmeyerflask/3004910.article, acessada em Abril 2018.

22. http://www.compoundchem.com/2016/06/28/erlenmeyer/, acessada em Abril 2018.

23. https://commons.wikimedia.org/wiki/Category:Emil_Erlenmeyer\#/ media/File:Emil_Erlenmeyer.jpg, acessada em Abril 2018.

24. https://pt.wikipedia.org/wiki/Kitasato, acessada em Abril 2018.

25. Trofa, A. F.; Ueno-Olsen, H.; Oiwa, R.; Yoshikawa, M.; Clin. Infect. Dis. 1999, 29, 1303.

26. Bastos, A. R.; Afonso, J. C.; Quim. Nova 2015, 38, 749

27. https://commons.wikimedia.org/wiki/File:Shibasaburo_Kitasato.jpg, acessada em Abril 2018.

28. Jensen, W. B.; J. Chem. Educ. 2006, 83, 1283.

29. https://www.chemistryworld.com/opinion/buchners-funnel/3004902. acessada em Maio 2018.

30. https://commons.wikimedia.org/wiki/File:Ernst_Buechner_im_Foyer_ der_Villa_B\%C3\%BCchner,_Pfungstadt.jpg, acessada em Abril 2018.

31. https://www.chemistryworld.com/opinion/buchners-funnel/3004902. article, acessada em Abril 2018

32. https://www.chemistryworld.com/opinion/classic-kit-hirschsfunnel/3004919.article, acessada em Abril 2017.

33. Terra, J.; Rossi, A. V.; Quim. Nova 2005, 28, 166.

34. Wisniak, J.; Revista CENIC 2014, 45, 184.

35. http://allchemy.iq.usp.br/metabolizando/beta/01/gay.htm, acessada em Abril 2018.

36. Rosenfeld, L.; Four Centuries of Clinical Chemistry, $1^{\text {st }}$ ed., CRC Press: New York, 1999.

37. https://www.chemistryworld.com/opinion/classic-kit-mohrsburette/3004927.article, acessada em Abril 2018.
38. https://pootoogoo.wordpress.com/2015/02/15/elevator-to-espressoepisode-1/, acessada em Abril 2018.

39. Duval, C.; J. Chem. Educ. 1951, 28, 508

40. http://www.chem.ucalgary.ca/courses/351/laboratory/meltingpoint.pdf, acessada em Abril 2018.

41. http://www.chem.ucalgary.ca/courses/351/laboratory/boilingpoint.pdf, acessada em Abril 2018.

42. https://commons.wikimedia.org/wiki/File:Johannes_Thiele_ca1890.jpg, acessada em Abril 2018.

43. https://www.theguardian.com/technology/2013/may/31/google-doodlejulius-richard-petri-dish-inventor, acessada em Abril 2018.

44. https://pt.wikipedia.org/wiki/Robert_Koch, acessada em Abril.

45. https://www.nobelprize.org/nobel_prizes/medicine/laureates/1905/kochbio.html, acessada em Abril 2018.

46. Ihde, A. J.; The Development of Modern Chemistry, Revised edition, Dover Publications: New York, 1984.

47. https://commons.wikimedia.org/wiki/File:Julius_Richard_Petri.jpg, acessada em Abril 2018.

48. https://sr.wikipedia.org/wiki/\%D0\%94\%D0\%B0\%D1\%82\%D0 $\%$ BE\%D1\%82\%D0\%B5\%D0\%BA\%D0\%B0:\%D0\%88\%D1\%8 $3 \% \mathrm{D} 0 \% \mathrm{BB} \% \mathrm{D} 0 \% \mathrm{~B} 8 \% \mathrm{D} 1 \% 98 \% \mathrm{D} 1 \% 83 \% \mathrm{D} 1 \% 81 \_\mathrm{D} 0 \% \mathrm{~A} 0 \%$ D0\%B $8 \%$ D $1 \% 85 \%$ D0\%B0\%D1\%80\%D0\%B4_\%D0\%9F\%D0 $\%$ B5\%D1\%82\%D1\%80\%D0\%B8.jpg, acessada em Abril 2018.

49. https://www.chemistryworld.com/opinion/classic-kit-ostwaldsviscometer/3004929.article, acessada em Abril 2018.

50. https://pt.wikipedia.org/wiki/Wilhelm_Ostwald, acessada em Abril 2018.

51. https://www.chemistryworld.com/opinion/classic-kit-soxhlet extractor/3004940.article, acessada em Abril 2018.

52. Jensen, W. B.; J. Chem. Educ. 2007, 84, 1913.

53. http://www.maxlabor.com.br/blog/para-que-serve-o-extrator-soxhlet/, acessada em Abril 2018.

54. https://collections.nlm.nih.gov/catalog/nlm:nlmuid-101429529-img, acessada em Abril 2018.

55. Melchior, M.; Boeck, P.; Anais do Encontro de Debates sobre o Ensino de Química, Santa Cruz do Sul, Brasil, 2014.

56. Richter, C.; Schwan, F.; Polanczyk, F. R.; Leite, F.; Anais do Seminário de Ensino, Pesquisa e Extensão da UFFS, Chapecó, Brasil, 2015.

57. https://twitter.com/hashtag/ChemGlass?src=hash, acessada em Abril 2018

58. http://boletim.sbq.org.br/noticias/2018/n3106.php, acessada em Abril 2018. 